\title{
DISCURSO PRONUNCIADO EL 19 DE NOVIEMBRE DE 1942 EN LA VELADA SOLEMNE QUE CON MOTIVO DEL CENTENARIO DE LA CORPORACIÓN, SE CELEBRÓ EN EL TEATRO MUNICIPAL DE SANTIAGO
}

\author{
Juvenal Hernández Jaque
}


Hernández, Juvenal. Discurso pronunciado el 19 de noviembre de 1942 en la velada solemne que con motivo del centenario de la corporación, se celebró en el Teatro Municipal de Santiago. Anales de la Universidad de Chile. Número conmemorativo del Centenario de la Universidad de Chile, 1943. 


\section{DISCURSO PRONUNCIADO EL 19 DE NOVIEMBRE DE 1942 EN LA VELADA SOLEMNE QUE CON MOTIVO DEL CENTENARIO DE LA CORPORACIÓN, SE CELEBRÓ EN EL TEATRO MUNICIPAL DE SANTIAGO}

Excmo. señor Presidente de la República y Patrono de la Universidad de Chile, Señor Ministro de Educación Pública, Señores Ministros de Estado, Señores Rectores y Delegados de países amigos, Señores Decanos y Directores Generales de Educación, Señores Profesores, Egresados y Estudiantes, Señoras y Señores:

La Universidad de Chile cumple cien años de vida. En un día como hoy, el 19 de Noviembre de 1842, el Presidente de la República, General don Manuel Bulnes, y su Ministro de Justicia, Culto e Instrucción Pública, don Manuel Montt, firmaban la resolución legislativa que daba forma al Reglamento Orgánico de esta casa.

Más tarde, el 17 de Septiembre de 1843, cuando el sol de fines de invierno ponía su delgado toldo de oro sobre la ciudad, y cuando las tiernas yemas de los árboles empezaban a lucir la gracia de sus colores, llegaba hasta este mismo sitio -antigua sede de la Universidad Real de San Felipe- una larga, gallarda, emocionante columna de viandantes. Había partido de la casa de Gobierno. Iban en la comitiva el Presidente de la República y sus Ministros, representantes de los demás poderes públicos y comisiones de Institutos Docentes y Culturales de la Capital.

El desfile brillaba en admirable policromía. A la austera severidad del negro traje de las autoridades, sucedía el dorado de las borlas y mucetas de los doctores de la Universidad dieciochesca de San Felipe; al sencillo vestido talar de los sacerdotes seguía el vistoso uniforme de los militares; al opulento hábito de los prelados acompañaba la levita solemne de los senadores, diputados, profesores y municipales. La marca de los caminantes resultaba, asimismo dispar. A los graves y sosegados pasos de los varones maduros, les precedía la columna liviana y ágil de los alumnos del Instituto Nacional. La banda de la escolta del Presidente llenaba el amplio espacio de las calles con la hermosa música, de marciales y rítmicos toques, del Himno Nacional de Manuel Robles.

Por la solemnidad de la ocasión, por la calidad del concurso, por el valor del contenido, ha sido aquel desfile, señores, uno de los más significativos y singulares de nuestra Historia Patria.

Cuando el solo estaba en el cénit, don Manuel Montt declaró instalada, en breve y sobria pieza oratoria, esta casa de estudios generales que es nuestra Universidad. Continuó en el uso de la palabra el sabio Bello en un discurso magistral, que trazó para siempre las bases que habrían de informar la tradición de nuestras aulas, y cerró el acto el Secretario General de la Corporación, el poeta Salvador Sanfuentes, leyendo los temas 
que cada Facultad proponía para los certámenes del año siguiente. Al término de la primera parte de esta ceremonia, veintiún cañonazos, desde los hombros de Santa Lucía, rasgaron el silencio con el vibrante estruendo de sus detonaciones, anunciando a los ámbitos todos de la Nación que la Universidad había nacido.

Pero el acto no terminó en ese lugar. La comitiva se puso de nuevo en marcha. Dirigióse hacia el Domus Dei catedralicio, para agradecer al Altísimo la nueva creación. A los graves y magníficos tonos del órgano se unieron, en armoniosa musicalidad, los acentos reverentes del himno más solemne de la liturgia católica: Te Deum laudamus...

La alegría de aquel momento era natural. Es cierto que la Universidad de San Felipe, hija de su época, fué la necesaria resonancia del medio que dió vida, y, que, con todos sus defectos y limitaciones, hizo el bien que le era dable por la cultura; pero los ideales de la Revolución de 1810, que aspiraba a la liberación del hombre por la educación democrática, no se habían cumplido.

Con su cesación se liquidaba todo un pasado: iba a nacer algo nuevo de aquel auto de fe de una época. Cuando don Mariano Egaña, Ministro del Presidente Prieto, declaraba extinguida a la vieja institución universitaria colonial, no hacía sino abrir las ventanas del ambiente chileno al nuevo espíritu del tiempo, en cuyo clima había vivido él en Europa.

Con la liberación del dominio español, Chile renacía a una nueva vida social y espiritual. Los primeros años de la República, fueron, necesariamente, los de una lenta formación. La generación que había hecho la independencia, que había luchado contra los resabios coloniales, no podría sino contribuir a estimular toda preocupación por la enseñanza. Así se explica cómo, a la par que preparaba la reconstrucción de la Patria, tras los días de Chacabuco y Maipo, reabrió sus puertas el Instituto Nacional, al que afluían como al caudal madre los diversos cauces, el antiguo Convictorio Carolino, los catedráticos sanfelipenses, la Academia de San Luis, etc.

Mientras el país consolidaba sus instituciones, en ardua lucha contra la inexplicable anarquía que acompaña siempre a los pueblos recién nacidos, una era de prosperidad contribuyó a prestigiar al país en el continente. Trascendía de nuestras fronteras el eco de los primeros progresos y de una incipiente actividad cultural que alentaba una juventud promisoria y la autoridad de muchos hombres ilustres. Los primeros periódicos literarios, los cenáculos iniciales, el arribo al país de algunos emigrados notables, que arrojaban hasta nosotros las marejadas políticas, fué creando un clima propicio para el florecimiento de las letras y para el estímulo de las ideas. Nacía el movimiento literario de 1842, fecha auroral para las instituciones de la República. No es ya tan sólo la enseñanza, cuyo interés representaba «una intención preferente del Estado», según lo establecía la Constitución de 1883, sino que ese anhelo creador que enriquece a los pueblos con el tesoro de las fuerzas espirituales. Los ecos del romanticismo europeo resonaban en Chile en espectaculares controversias, riñéndose en nuestro medio la ardorosa batalla de clásicos y reformistas. 
¡Magnífico periplo éste, alrededor de los viejos ensueños de Europa, que al llegar a nuestras playas se renuevan y vivifican de acuerdo con nuestras modalidades!

A fines de la primera mitad del siglo pasado, los grupos de mayor desarrollo intelectual de la sociedad chilena viven en la misma brega ideológica, hecha la salvedad de distinto medio geográfico y de las razas distintas, que los pueblos más cultos de Europa. Las ideas liberales que cunden en el viejo mundo son las mismas que enardecen el pulso de la avanzada juvenil de 1842; las doctrinas y la substancia partidista de los más renombrados escritores de esa época, allende el Atlántico, son las mismas que convienen y ajustan con la propaganda de los más audaces en ese momento interesantísimo de nuestro despertar a una vida ciudadana más alta y conforme con los principios de una verdadera democracia. Los hombres que en Inglaterra y Francia son bandera no sólo de una escuela determinada, sino también de las juventudes de Europa, pasan a convertirse entre nosotros en verdaderos símbolos del pensamiento universal.

La mejor antena de ese movimiento político y literario es don José Victorino Lastarria. Los trasandinos ilustres que vinieron a Chile, Sarmiento, Mitre, Alberdi, López, Gutiérrez, Piñero, Peña y Gómez, encontraron en aquel grande hombre el más leal y, al mismo tiempo, el más digno y preparado de sus contradictores cuando la polémica de los estilos agitó la atmósfera de los círculos literarios de Santiago. ¡Tiempos caballerescos en que los enemigos por principios se saludaban galantes al empezar la lucha y se abrazaban fraternalmente después de la palestra!...

No queremos hacer una lista fatigosa de nombres para referirnos a esa generación entusiasta. Bástenos decir que en ese grupo empiezan a surgir, en sus mocedades heroicas, hombres de lo más insigne que ha tenido América española, como Francisco Bilbao, Miguel Luis y Gregorio Víctor Amunátegui, Alberto y Guillermo Blest Gana, Manuel Blanco Cuartín, y esa figura apostólica de don Manuel Antonio Matta, que irradia con sus ampos luminosos uno de los capítulos más interesantes de nuestra lucha democrática por la libertad civil.

En el remanso del tiempo, apagado el brío y el calor de los hombres que impugnaron la tarea de esos precursores, podemos contemplarlos ahora a través de las nombres perspectivas de la Historia con el cariño y el amor que ellos merecen.

Para algunos de aquellos jóvenes de la llamada generación del 42, el destino reservó sitiales de distinción y de respeto. Muchos de ellos, sin embargo, quebraron sus alas antes del vuelo superior, sin fuerzas suficientes para embriagarse en las cimas erguidas de una alta inspiración, sea ésta en las lides jurídicas, sea en los debates del parlamento, sea en la tribuna pública, sea en la cátedra, sea en el rumor cada vez más tempestuoso de la prensa diaria. ¡No importa!. .. Ellos, los que nada consiguieron ni lograron en su amor por las formas perfectas del espíritu merecen, también, el recuerdo agradecido de las generaciones de hoy. Fueron aquellos soñadores chilenos -como se ha dicho- cual esos obreros de las catedrales góticas cuya construcción duró a veces más de un siglo. Modestos, resignados con su suerte obscura, iban poniendo un ladrillo sobre otro con la convicción profunda de que no verían jamás su obra realizada; pero sujetos, al mismo tiempo, a la hermosa ilusión de que sus hijos o quizás sus nietos, o no importa qué descendientes suyos, verían un día con los ojos anegados de dicha elevarse augusta en 
el cielo de Europa la enorme cruz sacra sujeta a su base a la torre más destacada de la magna catedral.

En medio de este cuadro adquiere sus formas la Universidad de Chile. Al franquear sus puertas, asumían las cátedras las figuras más representativas de la cultura nacional y algunos extranjeros eminentes que se hicieron protagonistas del movimiento: Domeyko, García Reyes, Sanfuentes, Tocornal y Sazié, De la Barra y Gorbea, Egaña, Güemes, Valdivieso y Donoso. El magisterio de don Andrés Bello apadrinaba en su cuna a la recién nacida. Era como el hada madrina que iba a velar por sus primeros pasos y a constituirse en el amparo y guía de su organización incipiente.

Jamás en los anales de la educación Chilena hubo un hombre que influyera de manera más definitiva y profunda en los destinos de nuestra patria. La acción del sabio venezolano como pedagogo, como redactor del Código Civil, como inspirador de las relaciones internacionales, como maestro de la lengua castellana, y en fin, como varón probo y docto, se ha hundido de tal modo en las raíces de la formación republicana de nuestro país, que bien podría llamarse a ésta, su patria de adopción, la patria de Bello. Por mucha que sea nuestra gratitud, nunca hemos de pagar en lo justo lo que este maestro de pueblos hizo por Chile y los chilenos.

Desde los días de su creación, la historia del desenvolvimiento de la Universidad se confunde con la del desarrollo de las instituciones de la República: dura brega contra la obstinación de las fuerzas negativas que coartan los mejores vuelos de la inteligencia.

Pero, bien comprenderéis, señores, que estoy en la imposibilidad de hacer siquiera un examen sintético de lo que fueron las actividades universitarias durante una centuria de vida. Apenas si puedo invocar el recuerdo cariñoso de los que me antecedieron en este cargo de honor y de confianza que hoy desempeño por mandato de los señores profesores. Desde la eternidad nos alimenta día a día el espíritu invisible de Barros Arana, Aguirre, Letelier, etc. y nos reconforta la presencia de los que aún viven y comparten nuestros anhelos y esperanzas, sobre todo la nobilísima figura de don Domingo Amunátegui, que es para nosotros como un símbolo de autoridad tutelar en cuyo corazón se abroquela, como en una armadura de amor, la suave ternura paternal de muchas generaciones de maestros.

Desde entonces maestros y discípulos, en incesante renovación, han ido dejando en las aulas de las distintas Facultades la huella de su paso y el recuerdo de sus voces; las vigilias pasadas en cada época, han formado en el ambiente universitario una compenetración de anhelos superiores semejantes al que ha hecho la grandeza de las universidades europeas, y ha creado en nuestro país la conciencia democrática que ha permitido la evolución institucional, mucho más uniforme e indivisible que las definidas en las constituciones y las leyes. Porque, a pesar de las críticas que alguna vez hayan podido 
formularse, inspiradas en motivos ideológicos circunstanciales, la Universidad ha realizado una profunda labor educadora a la vez que instructiva, primero en los núcleos bulliciosos de las bregas estudiantiles y después en los estrados profesionales del mundo externo. Es allí donde se construyen las uniones más férreas de la vida colectiva para consolidar, en su medida, la suprema y última armonía de los grupos sociales que las tormentas de nuestra historia política lanzaron a veces, disgregados y antagónicos, hasta hacer peligrar las bases morales de nuestra organización estatal.

Surgida la Universidad en hora muy propicia, ha renovado día a día los frutos, cada vez mejor sazonados, de su intenso cultivo de almas, de su activo taller de inteligencias para los artífices del progreso chileno del presente y del porvenir. Muchos de sus hijos despejaron a costa de cruentas heridas la obscura selva de las discordias lugareñas y de los prejuicios, y muchos han pasado también a la región de los inmortales para señalar a sus descendientes la ruta de las conquistas necesarias para nuestro desarrollo y grandezas futuros. Porque no ha habido actividad alguna de bien colectivo, durante un siglo de nuestra historia, que no haya tenido su origen en el esfuerzo de nuestros laureados. Todos ellos han sido en la vida pública, en la privada del trabajo o del estudio, incansables obreros del bienestar de la patria común, y una dilatación en espacios más vastos, de las fuerzas efectivas y espirituales que la Universidad, por sus estímulos, contribuyó a pulimentar y acrecentar en ellos.

A la sombra de esta Alma Máter se ha formado un ejército de maestros que luchan, con la lámpara encendida de la educación, por romper la tenebrosa condición de la ignorancia; los que formulan el Derecho, resguardan la augusta majestad de la justicia y dirigen nuestra organización política; los que en cada minuto de su vida cuidan de la salud pública y amparan en su celo las reservas vitales de la raza; los que laboran en la industria; tienden puentes, trazan caminos y arrancan codiciosos de nuestra madre tierra sus inagotables tesoros; los que empuñan la mancera del noble arado en la apacible fertilidad de nuestro valle central o su ganado apacientan en las campiñas sureñas; $y$, en fin, todos cuantos se sintieron penetrados por el ansia suprema de saber y quisieron consagrarse a la ciencia por irresistible atracción de la verdad, en las profundidades del selo, en los misterios de la vida vegetal o animal, en los azules abismos del espacio, o en los abismos, acaso más impenetrables del alma humana.

Y no lo hicieron por exclusivo espíritu de lucro. En el seno de la convivencia universitaria, afrontando las reacciones de la controversia, aprendieron que la inter-dependencia social del hombre es una hecho real, susceptible de comprobación directa; que el hombre no lo es todo ni lo puede todo, que la perfección no brota sino del conjunto, de la comunidad. Y si el mundo camina hacia la negación del hombre como sujeto de derecho para proclamar exclusivamente sus deberes, ya no deben existir las profesiones liberales, y los títulos que la Universidad expide sólo habilitarán para ejercer una función social al servicio de una causa de bien colectivo.

Cada día afianza nuestra Casa de Estudios este concepto educativo. Además de la eficiencia profesional de nuestros egresados, nos interesa su espíritu social. Y éste es, tal vez, el secreto de su fuerza moral y de su prestigio indestructible, que se expande y afianza cada día, porque es la levadura generatriz de todas las transformaciones. Sobre la base in- 
conmovible de la tradición, que es el fundamento de toda patria que aspire a perpetuarse, cada promoción levanta su propia fábrica y representa sus exclusivos anhelos y potencias. Ningún cambio, ningún progreso, ninguna conquista del espíritu la deja indiferente. Es como el arca santa de la cultura chilena cuyo contenido se renueva incesantemente, de generación en generación, de acuerdo con los moldes y las evoluciones del mundo, sobre la cual puede la patria levantar su edificio en la seguridad de que ha de ser eterno.

La Universidad de Chile procura armonizar su medio de acción, exaltando los valores raciales y abandonando todo aquello que no se amolda a nuestras características, descendiendo al seno de la vida chilena misma para acercar la verdad a todo mundo, es decir, para conocer los propios problemas y tratarlos con amor verdadero. En los estudios universitarios debe dominar siempre el esfuerzo de la inteligencia en la investigación científica, el propósito irreductible de descubrir la verdad por sí misma, la aspiración inquebrantable de descifrar lo desconocido. Ni el maestro ni el alumno serán, de este modo, un mero transmisor o receptor de conocimientos, sino por el contrario, en una aspiración común de perfeccionamiento, ambos han de sentirse protagonistas y cooperadores de una misma finalidad. Por eso he dicho en alguna ocasión que la reforma universitaria, más que motivo de ley, es un estado espiritual que se alcanza por una acción y coordinación inteligente de profesores y alumnos.

Nuestras Escuelas e Institutos han abandonado hasta donde ha sido posible el espíritu profesionalista que meció la infancia de la cultura chilena, como en el resto de la América hispana. No podrían ser más de lo que fueron ni ofrecer otros frutos que los contenidos en su propia savia; pero un impulso renovador ha sacudido los viejos cimientos especulativos para transformarlos en centros de incesante labor experimental de todas las cualidades de la materia, de todas las fuerzas del mundo físico y social, y en un foco de luz y de calor donde germinan y toman formas prolíficas los sentimientos de solidaridad humana en que se funden las sorprendentes evoluciones del espíritu universal.

Sólo así pueden los pueblos ser verdaderos creadores de cultura. La investigación científica es lo que constituye el alma de toda universidad que cumpla honradamente su misión. Formar, desarrollar y estimular el espíritu científico en el ritmo de las generaciones, es ofrecer a la nacionalidad bases inmutables de supervivencia y fortaleza, porque impone la verdad como rasgo de carácter colectivo, enseña a tener confianza en sí mismo, disciplina el carácter en la ansiedad tras la esperanza vivificante, y ennoblece el corazón por la bondad que inculca el trabajo.

Pero, cuando hablamos de ciencia como fuerza colectiva nacional y humana, nos referimos a la ciencia actual y concreta, que estudie los problemas positivos de la sociedad política, en busca de soluciones inmediatas, y en relación con las necesidades del medio social. Si la Universidad no se preocupa del medio social, no es más que un claustro cerrado y exclusivo que no cumple su misión civilizadora y sus fuerzas se perderán en el vacío. Ella está en la obligación, puesto que representa la cúspide de la arquitectura educacional del país, de procurar la armonía sobre la que se asienta la convivencia humana, modelando sus exigencias, actuando como niveladora de todos los elementos, puesto que el equilibrio y la paz social residen en la conciencia homogénea de los ciudadanos y en la mayor elevación de la inteligencia colectiva. 
Una Corporación de Altos Estudios es, pues, un instrumento capaz de obrar sobre el corazón y el cerebro de las distintas clases en que la sociedad prácticamente se divide, y, además, de la obra sistemática que realiza a través de las Facultades, practicando la investigación e impartiendo la alta cultura, tiene también el deber de participar al pueblo parte de su esfuerzo creador en la difusión de los primeros principios. Este resultado es el que se alcanza por la extensión universitaria.

La estabilidad y el progreso moral, social y político de una democracia moderna dependen de la difusión de su cultura, y el amor patrio y civismo verdaderos deben cimentarse sobre un entusiasmo inspirado por la universalización del saber. La influencia del conocimiento en el pueblo, de las verdades científicas enunciadas en la cátedra y renovadas en las posteriores comunicaciones de la extensión universitaria, contienen el estallido de las malas pasiones, moderan los apetitos y los odios insanos que nacen y viven de la irresponsabilidad, al par que engendran una efusión de amor por el bien, el respeto por el derecho ajeno, y abren al país el horizonte de ese reino ideal de paz, de libertad y de justicia con que soñamos siempre todos los que aspiramos hacia altísimos designios de un mayor bien humano.

Nuestra vieja casa se ha esforzado por cumplir esta responsabilidad social. En el curso de cien años, y sobre todo en lo que va corrido de este siglo, han desfilado por la cátedra libre los más altos exponentes del pensamiento chileno, de las ciencias, las artes y las letras americanas, y muchos personeros de las culturas milenarias de Europa; y en los bancos de nuestros Cursos, Conferencias, Escuelas de Temporada, Exposiciones y Audiciones, se han sentado miles y miles de ciudadanos, desde las más altas jerarquías sociales, hasta las más modestas, igualados todos en su afán de ir a buscar cultura por la cultura. Así se ha exteriorizado la Universidad de Chile en el ambiente social y político de la Nación.

Todo país que tiene el anhelo de perdurar y de salvar su historia, orienta las fuerzas vivas de que dispone hacia fines precisos y determinados, y no existe, de seguro, otra fuerza viva que supere la inteligencia de un pueblo para mover su propio destino. La universidad es el mejor acicate del progreso nacional, y por eso, nuestros Gobiernos, como en todos los países que tienen tradiciones espirituales de siglos, le han otorgado el fuero de su autonomía. Las demás instituciones públicas pueden caer y transformarse al compás de las alternativas sociales y políticas del momento; pero la Universidad, cuyo objetivo se pierde en el infinito, que sirve al interés permanente y supremo del grupo social, debe mantenerse siempre en funciones, haciendo la labor silenciosa de los que buscan el ideal frente a las zozobras de la realidad. La cooperación de la cultura dentro de la organización política se produce espontáneamente, sin más estímulo que ella misma.

La autonomía docente de que hemos disfrutado engendró en nosotros un profundo sentido de responsabilidad para perseverar en los afanes de crear una ciencia nuestra, que no por ser tal, será menos universal ni humana; y la presencia de S. E. el Presidente de la República y sus Ministros en esta solemne recordación, que agradecemos como un señalado honor, nos indica que hemos hecho buen uso del privilegio que nos concedió definitivamente el Estatuto de 1931. 
La Universidad agradece también, y aprecia en cuanto vale, la presencia de los señores Rectores, Decanos y Delegaciones de los países amigos, porque ella nos dice que han sido escuchados nuestros requerimientos de cooperación intelectual, y que ya estamos a un paso de formar en este Hemisferio la «Sociedad de los Espíritus» de que hablaba Paul Valery, mucho más fuerte, sin duda, que las alianzas contractuales cuando el sentimiento y la convicción no las sustentan. En la hora dolorosa que vive el mundo que fué la cuna de nuestra civilización, los países de América están obligados a pensar en su propia historia, y a buscar, en las fuentes que les son comunes, los medios para llegar a una paz tan inalterable como verdadera.

He aquí, señoras y señores, en brevísima síntesis, lo que ha sido la Universidad de Chile y lo que aspira a ser en el futuro, a pesar de lo que ha dado en llamar la «misión de la Universidad», es algo que aun permanece en pie con dos formidables signos de interrogación para pedagogos y humanistas. Mas, si el problema es de urgente trascendencia, y la respuesta continúa en suspenso en los centros de más escogida preparación con que se honra el pensamiento contemporáneo, debemos señalar, sin embargo, que la práctica de los hechos ayuda a reducir los escollos impeliendo a maestros y alumnos a buscar en la penumbra de los sucesos actuales nuevas luces que ayuden a realizar en la Universidad un esfuerzo para encontrar esa ecuación ambicionada que dé a la Patria educandos que hagan coincidir su propio destino con el destino y el interés de la colectividad.

Esta casa, ahora centenaria, ha sido desde los días de Bello, incansable en sus afanes de perfeccionarse. Fué una etapa magnífica de las rectorías de antaño que cumplió con honra su ciclo evolutivo.

Pero la sociedad humana es hoy un tren en marcha. El carácter meramente profesional y humanístico de las universidades de la décimonona centuria no satisface los anhelos de la época. La Universidad del siglo XX tiende a preocuparse de las múltiples cuestiones de la vida mundial que hoy enfoca, con potentísimos reflectores, la afiebrada curiosidad de los hombres. Pero estas ansias deben ser dirigidas; esta inquietud de torrente hay que derivarla hacia cauces más hondos, donde las cualidades del pensamiento superior mantengan, como en las normas de la tradición clásica, su jerarquía excelsa. «Es, pues, cuestión de vida o muerte para Europa -opina Ortega y Gasset- rectificar tan ridícula situación. Para ello tiene la Universidad que intervenir en la actualidad como tal Universidad, tratando los grandes temas del día desde su punto de vista propio -cultural, profesional y científico-. De este modo no será una institución sólo para estudiantes, un recinto ad usum delphinis, sino que, metida en medio de la vida, de sus urgencias, de sus pasiones, ha de imponerse como un poder espiritual superior frente a la prensa, representando la serenidad frente al frenesí, la seria agudeza frente a la frivolidad y la franca estupidez. Entonces volverá a ser la Universidad lo que fué en su hora mejor: un principio promotor de la historia europea.»

Eso que el filósofo ambiciona para su continente, lo soñamos nosotros para Chile y los pueblos de América. En esta brega estamos. Las puertas de la Universidad de Chile 
encuéntranse abiertas hacia todas las ideas que ennoblecen, en el estudio, el paso de las generaciones; y se abren también para las juventudes de la América toda, aspirando a formar, en el seno acogedor de sus aulas, esa atmósfera necesaria y fraterna que en un día del porvenir, bajo el signo davídico del Arca de una Alianza decretada ya por las voces de la sangre y del idioma, haga de los pueblos del Nuevo Mundo una sola y grande patria sostenida por la fe de su tradición insigne, auspiciada por la libertad de sus instituciones democráticas, defendida por la fuerza santa del Derecho, que tuvo en Bello un apóstol y en Chile la cátedra primera en que resonaron sus enseñanzas...

Maestro:

Con motivo de cumplir vuestra Universidad cien años de vida, os presento el homenaje de sus autoridades, de sus profesores, de sus egresados y de sus alumnos. Desde la cumbre de la inmortalidad podéis mirar, con la templanza de un dios griego, el luminoso camino recorrido y vislumbrar en la lejanía del horizonte, la aurora de la gloria... 